\title{
The antecedents of green innovation performance: A model of learning and capabilities
}

\begin{abstract}
Environmental management and green practices have a narrow linkage with firm innovativeness. Companies that are pioneers in green innovation strategies might reach and sustain competitive advantages. Thus, successful green innovation performance (GIP) helps firms to achieve greater efficiency as well as to establish and strengthen their core competences. This study focuses on the dynamic capabilities (DC) and ordinary capabilities (OC) like antecedents of GIP, and the relationship between these constructs. Proposing a mediation model to analyze both direct and indirect relationship, this study applies variance-based structural equation modeling through a partial least squares to a sample of 112 firms from the Spanish automotive components' manufacturing sector. The results suggest that both the direct effect and indirect effect of capabilities (DC and OC) on GIP are positive and significant, and improve the prediction of firm's GIP. Furthermore, the structural model supports that DC influence GIP by reconfiguring relationship-learning capabilities (a type of OC).
\end{abstract}

Keywords: Dynamic capabilities; ordinary relationship learning capabilities; green innovation performance; Partial Least Square 


\section{Introduction}

The ecofriendly impact of the human behavior is a constantly growing global concern for people, policy makers, countries, and organizations. Governments have applied corrective policies in the last years to diminish or palliate such environmental damage (Chen, 2008). Companies are not immune to this reality. On the contrary, as every multifaceted system in search for the equilibrium that will ensure long-term survival, companies should respond successfully to a dual adjustment dynamic. On the one hand, to reach a clear level of market efficiency, which involves enhancing the use of its resources and capabilities, which always have a limit-competitive adjustment. On the other hand, to overcome a certain degree of consistency with the society within which the organization operates-legitimacy adjustment.

In order to subsist inside the presently stormy and hypercompetitive scenarios, companies must foster innovativeness. To this end, companies must remain up to date of the manifold market changes, fluctuations, and tendencies that are persistently arising. This objective involves a customer orientation, and a green orientation strategy. In this line, the ultimate aim of developing a green product/service innovation strategy deals with enhancing the firm's survival and performance (Laforet, 2009).

The increasing societal demands compel companies to integrate sustainability topics into their regular activity so that companies can reach their social, environmental, and economic goals. Two major driving forces promote green management (Chen, 2008): (1) the international set of norms and regulations concerning environmental protection, and (2) the consumers' environmental consciousness (Chen et al., 2006). Whatever are the goals that lead companies to undertake environmental managementcomplying with environmental laws and regulations, becoming more competitive, gaining legitimacy, etc.- integrating environmental sustainability issues into business 
strategy and greening the innovation process are becoming a strategic opportunity for companies (Porter \& Reinhardt, 2007). Hence, following several studies, environmental management and green practices present a narrow linkage to firm innovativeness (Aragón-Correa, 1998; Pérez-Valls et al., 2015).

In this sense, companies that are pioneers on green innovation strategies might be able to reach and sustain competitive advantages. Thus, successful green innovation performance (GIP) helps companies to achieve greater efficiency as well as to establish and strengthen their core competences and to enhance their green image. Consequently, all these actions may eventually enable companies to reach superior performance and higher profitability (Chen, 2008).

Literature on the capabilities-based view and the knowledge-creating view of the firm focuses on both ordinary capabilities (OC) and dynamic capabilities (DC) as the most valuable antecedents that provide sustainable competitive advantage, and on interaction as a key component for the access, attainment and development of new knowledge that is necessary to improve the results of innovation. Interaction may take place within a firm and between firms and other organizations. Firms use different networking mechanisms to access knowledge outside their frontiers. Extensive literature discusses various organizational features corresponding to different mechanisms that facilitate knowledge flows among different actors and enable relational learning activities.

This situation is even more critical in natural-resources intensive sectors, such as the automotive industry, which causes an important environmental impact. For this reason, firms must consider any measure aiming at improving those sectors' environmental efficiency and at enhancing the GIP. However, little empirical research addresses the question of how different capabilities, as antecedents, affect the improvement of GIP. This study focuses on the automotive sector. 
This study examines the extent to which the existing internal capabilities of firms and their interaction with external sources of knowledge-enhancement relationship learning — affect their level of GIP. Section two reviews the theoretical framework that forms the basis of this empirical analysis. Section three presents an empirical analysis building on information about 112 firms from the Spanish automotive components' manufacturing sector. Finally, section four summarizes the results and discusses the main points arising from the analysis. The results confirm the positive role on GIP of both the direct effect and indirect effect of firm capabilities. Furthermore, the findings support that DC influence GIP by reconfiguring relationship-learning capabilities and accessing knowledge outside firms' boundaries.

\section{Theoretical background}

\subsection{Green Innovation Performance (GIP)}

In the environmental era, firms should integrate ideas to protect the environment. For this reason, green innovation is essential for firm's business management. An efficient management can create value, leverage a competitive advantage, and increase the firm's performance (Chang \& Chen, 2013).

Innovation is an important way to mitigate or avoid environmental damage. Green technologies provide two main benefits for organizations: the commercial rewards from creating environmentally sustainable products, and the financial benefits that can increase competitiveness. Customers around the world want and expect to purchase ever more environmentally friendly products and services. Certainly, green innovation is a strategic need for firms which offers a great chance for meeting customers' demands without harming the ecosystem. 
Historically, firms have seen investing in eco-friendly behaviors as an excessive investment, but today's strict ecological rules and the prevalence of environmentalism are changing competitive strategies, policies, and patterns for firms (Porter \& Reinhardt, 2007). The 'green' label is an incentive for continuous innovation, creating new market opportunities for firms to satisfy new consumer demands and thus create value and improve performance.

Green innovation can consist of either green products or green processes. Green innovation comprises innovation in technologies for energy saving, pollution prevention, waste recycling, green product designing, and corporate environmental management (Chen et al., 2006).

\subsection{The link between dynamic capabilities, relationship learning-as ordinary} capabilities - and the firm's GIP

In line with the resource-based view (RBV), the differences in performance between companies owe to their specific sets of resources and capabilities. Therefore, such resources and capabilities are the source of competitive advantage (Helfat \& Peteraf, 2003). The RBV assumes the heterogeneous distribution of resources and capabilities among companies and its maintenance over time (Ambrosini \& Bowman, 2009).

At the current period of widespread crisis, with a significant shortage of resources in all sectors, organizations need more than ever to be able to distribute their available resources among the alternatives, to try to adapt in the best way and as quickly as possible to the turbulence of the environment (Prahalad \& Ramaswamy, 2004). Consequently, organizations must develop DC to evolve, advance, grow, adapt, and, ultimately, survive. Such DC development allows companies to sit some firm foundations that support their strategy. Nonetheless, although DC's outlook follows the 
RBV (Makadok, 2001), and RBV highlights resource combinations selection, DC emphasizes resource regeneration. This way, DC are the capacity of the firm to reconfigure resources into new combinations of ordinary-or operational—capabilities (OC).

The literature offers numerous definitions of DC. The concept of DC has undergone a terminological evolution thanks to the contributions and disagreements of different authors. Teece et al. (1997) first coin this concept and define DC as firms' ability to integrate, build, and reconfigure internal and external competencies to manage rapidly changing environments. Cepeda and Vera (2007) and Zahra et al. (2006) refer to DC as the processes to reconfigure a firm's resources and operational routines in the manner that its principal decision-makers envision and deem appropriate.

This article adopts Pavlou and El Sawy's (2011, p. 243) conceptualization. Extending earlier works by Teece (2007) (sensing the environment to seize opportunities and reconfigure assets), and Teece et al. (1997) (reconfiguring, learning, integrating, and coordinating), these authors propose a framework that contains four DC that function as tools that enable the reconfiguration of existing operational capabilities: (1) sensing, (2) learning, (3) integration, and (4) coordination capabilities.

Several authors propose the need to differentiate among types of processes and routines available in firms. Thus, Zollo and Winter (2002) and Winter (2003) distinguish between ordinary—operational—(zero-order) and dynamic (first-order) capabilities. Ordinary capabilities focus on the operational working of the firm, including both staff and line activities; these are "how we earn a living now" capabilities. Dynamic capabilities relate to the transformation of ordinary capabilities causing changes in the firm's products or production processes, or create new ordinary capabilities. 
Karna et al. (2015) distinguish five categories of ordinary capabilities: (1) operations/processes, (2) product/service/quality, (3) resources/assets, organization/structure, and (5) customer/supplier relationships. This study uses customer/supplier relationships because of the importance that the innovation literature grants to knowledge sharing and relational learning activities.

When firms share information and knowledge with customers and suppliers, they enhance their knowledge base, capabilities, and competitiveness through relationshiplevel learning. This framework broadly adopts the meaning from Cheung et al. (2011) and the original definition from Selnes and Sallis (2003, p. 86) of the relationshiplearning activities:

[Relationship learning activities are] "an ongoing joint activity between the customer and the supplier organizations directed at sharing information, making sense of information, and integrating acquired information into a shared relationship-domainspecific memory to improve the range or likelihood of potential relationship-domainspecific behavior".

Relationship learning is thus a process to increase future behavior in a relationship. This study proposes that relationships vary in terms of their relationship learning capabilities (RLC), and thus some relationships perform better because they have developed appropriate learning mechanisms. Following Selnes and Sallis (2003), this study's research model presents RLC as a construct comprising three ordinary capabilities: (1) information sharing capability (ISC), (2) joint sense-making capability (JSC), and (3) knowledge integration capability (KIC).

The foundation of cooperative nets between companies and stakeholders is critical in innovation progress (Bossink, 2002). Through alliances and relationships, organizations can effectively innovate by sharing complementary assets and skills (Powell, 1998). 
Organizations can consequently create partnerships, joint ventures, inter-firm nets, and R\&D conglomerates (Doz et al., 2000). This idea is the basis of Chesbrough's (2003) open innovation theory, which argues that companies can combine external and internal ideas and market pathways to take advantage of their technologies. A fruitful green innovation process requires collaboration and knowledge exchange with external stakeholders. Furthermore, many organizations lack knowledge and capabilities to foster green innovations. For example, in the automotive components' manufacturing sector, if a company needs to reduce its products' environmental impact-supposing that the company does so at many points in the supply chain and that the firm itself does not participate in all product manufacturing stages - collaboration with other companies in the product's value chain is necessary (Petruzzelli et al., 2011). Additionally, the sophistication of ecological problems forces firms aiming to perform green innovations to build a solid, broad net of links with their customers and suppliers (Ngai et al., 2008). These stakeholders are a source of eco-friendly knowledge and capabilities outside the firm's core domain. The relevance of RLC in developing green innovations is so essential.

The capabilities-based view of the firm proposes that, to gain competitive advantage, firms need OC, which let them operate their selected outlines of business efficiently, and DC, which assist them to promote existing OC or to create new ones (Karna et al., 2015). However, a strong debate exists over this field, "riddled with inconsistencies, overlapping definitions, and outright contradictions" (Zahra et al., 2006, p. 917). Even today, the relationship between DC, OC, and competitive advantage and performance remains controversial.

The literature provides extensive, although not general, evidence of the enhancing effect of DC and OC on innovation and performance (Karna et al., 2015). On the one hand, 
some authors and several empirical studies suggest a direct effect of DC on performance and competitive advantage (Karna et al., 2015; Teece, 2007; Teece et al., 1997). On the other hand, some authors disagree with this direct relationship between DC and performance. For instance, Helfat et al. (2007) decouple the notion of DC and performance and contend that DC do not unavoidably lead to competitive advantage, because although DC may change the resource base, DC may not create any valuable, rare, inimitable, and none-substitutable (VRIN) resources (Zahra et al., 2006; Eisenhardt \& Martin, 2010). This view questions the direct relationship between DC and performance. Instead, Pavlou and El Sawy (2011) propose an indirect relationship. These authors offer empirical evidence that DC indirectly influence performance by reconfiguring existing operational (ordinary) capabilities into superior ones that better match the changing environment. Therefore, Pavlou and el Sawy (2011) also differentiate between $\mathrm{OC}$ and DC, and argue that competitive advantage and performance come from new configurations of resources and OC, and not from DC per se, introducing the mediating role of $\mathrm{OC}$ in the relationship between DC and performance in new product development.

Recently, Karna et al. (2015) investigate the role of OC and DC as drivers of the financial performance of firms under different environmental conditions by metaanalyzing 115 empirical studies comprising 121 samples. Their results suggest that the performance effects of both types of capabilities are positive and similar in magnitude. Environmental dynamism reinforces the effects of both ordinary and dynamic capabilities. Furthermore, the two types of capabilities present a close association. These findings provide support for a moderate capabilities-based view of the firm, rather than one that considers dynamic capabilities as superior to ordinary ones. 
Therefore, Karna's study reaffirms the idea that variations in capabilities across firms are central to explaining variations in competitive advantages and performance.

H1: Dynamic capabilities relate positively to firm's GIP.

H2: RLC (like OC) relate positively to firm's GIP.

H3: DC relate positively to RLC (like OC).

H4: RLC (like OC) positively mediate the relationship between DC and GIP.

This study presents a research model with the relationships between DC, GIP, and RLC are related (Figure 1).

\section{Method}

\subsection{Data collection and sample}

This research focuses on the automotive components' manufacturing sector in Spainone of the fastest growing sectors in the country. Such industry presents a high knowledge intensity, innovativeness, and product-oriented products-mainly major automobile manufacturers (e.g., Ford, Citroen, Renault, Peugeot.). These companies provide components and highly customized products and services to large automakers.

On the one hand, these firms act as external knowledge sources for their client firms. On the other hand, they are increasingly becoming independent innovation creators. Most firms in the automotive components manufacturing sector are SMEs. Firms that incorporate the specialist knowledge and capabilities to develop effective green innovations create customer value and have an advantage regarding differentiating their products from their competitors.

The sample comes from a list of Sernauto, the Spanish association of automotive equipment and components manufacturers. From the 960 companies in the sector, 387 firms that carry out green innovation received the questionnaire. After two remainders, 
the study obtains 112 usable surveys, representing a response rate of $28.94 \%$. The low response rate for this sample owes to the fact that only top executives can answer the questionnaire.

\subsection{Measures}

This study uses a seven-point Likert scale from high disagreement to high agreement to measure the questionnaire items. The study uses 19 items from Pavlou and El Sawy (2011) to measure DC. Three dimensions define RLC: information sharing, joint sensemaking, and knowledge integration (Selnes \& Sallis, 2003). In the final scale, 17 items measure these three components. Finally, the study follows Chen et al. (2006) to measure GIP and its measurement includes eight items. The design of the measurement model presents reflective first-order dimensions (i.e., sensing capability, learning capability, integrating capability, and coordinating capability) and a reflective secondorder construct (i.e., DC). In this case, the study focuses on the common variance, that is, the variance common to the four dimensions. Because of space restrictions, readers may request a copy of the questionnaire to the corresponding author.

\subsection{Data analysis}

The study uses Partial Least Squares (PLS) path-modeling, a variance-based structural equation modeling (SEM) technique to test the model (Roldán \& Sánchez-Franco, 2012). PLS simultaneously enables the assessment of the reliability and validity of the measures of theoretical constructs (outer model) and the estimation of the relationships among these constructs (inner model) (Barroso et al., 2010). The following reasons justify the use of PLS: (1) this study aims at predicting dependent variables (Chin, 2010); (2) the sample ( $\mathrm{n}=112$ ) is small and, according to Reinartz et al. (2009), studies 
should apply PLS when the number of observations is lower than 250; (3) the research model is complex, both in the type of variables (first- and high-order constructs) and in the hypothesized relationships (direct and indirect or mediated effects); and (4) this study uses latent variables scores in the subsequent analysis for a predictive relevance (Hair et al., 2011). The study employs the SmartPLS 2.0 software (Ringle et al., 2005). The operationalization of the multidimensional superordinate constructs follows a twostep approach (Chin, 2010). Accordingly, the study optimally weights and combines the items for each dimension using the PLS algorithm to create a latent variable score. As a result, the dimensions or first-order factors became the observed indicators of the second-order construct, that is, the DC and RLC variables (Chin \& Gopal, 1995).

\section{4. $\quad$ Results}

The interpretation of the PLS model comprises two phases: measurement model (outer model), and structural model (inner model). This sequence ensures that the measures of constructs are reliable and valid before attempting to draw conclusions with respect to the relationships between constructs (Roldán \& Sanchez-Franco, 2012).

\subsection{Measurement model results}

The measurement model involves assessing reliability and validity. The model of measure is completely satisfactory (Tables 1 and 2). First, the individual reliability of items is suitable. Accordingly to Hair et al. (2014), the indicator's outer loadings should be higher than 0.707 . Hence, the individual item reliability is adequate (Carmines \& Zeller, 1979). Second, the construct reliability requirement is also adequate because all reflective constructs present composite reliabilities $(\rho c)$ greater than 0.7 (Nunnally \& 
Bernstein, 1994). These latent variables reach convergent validity because their average variance extracted (AVE) measures are over 0.5 (Fornell \& Larcker, 1981).

Finally, all variables present discriminant validity according to the Fornell-Larcker and the Heterotrait-monotrait (HTMT) criteria (Table 2). On the one hand, Fornell-Larcker involves comparing the square root of AVE with the correlations. For satisfactory discriminant validity, the diagonal elements (in bold) should be significantly higher than the off-diagonal elements in the corresponding rows and columns (Fornell-Larcker, 1981). On the other hand, the Heterotrait-monotrait (HTMT) ratio of correlations evaluates the average of the Heterotrait-Heteromethod correlations (Henseler et al., 2014).

Table 1. Measurement model: loadings, construct reliability and convergent validity

\begin{tabular}{|c|c|c|c|c|}
\hline Construct/dimension/indicator & Loading & Composite & Cronbachs & $\begin{array}{l}\text { Average } \\
\text { variance }\end{array}$ \\
\hline & & $\begin{array}{l}\text { Reliability } \\
(\mathrm{CR})\end{array}$ & Alpha & $\begin{array}{l}\text { Extracted } \\
(\mathrm{AVE})\end{array}$ \\
\hline Dynamic Capabilities (DC) & & 0.97 & 0.96 & 0.90 \\
\hline Sensing Capability (SC) & 0.92 & 0.89 & 0.84 & 0.68 \\
\hline DC_SC1 & 0.80 & & & \\
\hline DC_SC2 & 0.83 & & & \\
\hline DC_SC3 & 0.80 & & & \\
\hline DC_SC4 & 0.86 & & & \\
\hline Learning Capability $(L C)$ & 0.96 & 0.90 & 0.87 & 0.66 \\
\hline DC_LC1 & 0.83 & & & \\
\hline DC_LC2 & 0.75 & & & \\
\hline
\end{tabular}




\begin{tabular}{|c|c|c|c|c|}
\hline DC_LC3 & 0.74 & & & \\
\hline DC_LC4 & 0.84 & & & \\
\hline DC_LC5 & 0.87 & & & \\
\hline Integrating Capability (IC) & 0.94 & 0.94 & $\mathbf{0 , 9 3}$ & 0.78 \\
\hline DC_IC1 & 0.90 & & & \\
\hline DC_IC2 & 0.85 & & & \\
\hline DC_IC3 & 0.88 & & & \\
\hline DC_IC4 & 0.90 & & & \\
\hline DC_IC5 & 0.88 & & & \\
\hline Cordinating Capability $(C C)$ & 0.96 & 0.92 & 0.90 & 0.72 \\
\hline DC_CC1 & 0.95 & & & \\
\hline DC_CC2 & 0.86 & & & \\
\hline DC_CC3 & 0.87 & & & \\
\hline DC_CC4 & 0.68 & & & \\
\hline DC_CC5 & 0.89 & & & \\
\hline Green Innovation Performance (GIP) & & 0.91 & 0.91 & 0.93 \\
\hline GIP1 & 0.85 & & & \\
\hline GIP2 & 0.82 & & & \\
\hline GIP3 & 0.82 & & & \\
\hline GIP4 & 0.85 & & & \\
\hline GIP5 & 0.73 & & & \\
\hline GIP6 & 0.88 & & & \\
\hline GIP7 & 0.70 & & & \\
\hline GIP8 & 0.75 & & & \\
\hline Relationaship & & 0.97 & 0.95 & 0.91 \\
\hline
\end{tabular}


(RLC)

\begin{tabular}{|c|c|c|c|c|}
\hline Information Sharing Capability (ISC) & 0.97 & 0.90 & 0.88 & 0.59 \\
\hline RL_ISC1 & 0.78 & & & \\
\hline RL_ISC2 & 0.85 & & & \\
\hline RL_ISC3 & 0.77 & & & \\
\hline RL_ISC4 & 0.73 & & & \\
\hline RL_ISC5 & 0.80 & & & \\
\hline RL_ISC6 & 0.73 & & & \\
\hline RL_ISC7 & 0.67 & & & \\
\hline Joint Sensemaking Capability (JSC) & 0.94 & 0.85 & 0.77 & 0.60 \\
\hline RL_JSC8 & 0.77 & & & \\
\hline RL_JSC9 & 0.86 & & & \\
\hline RL_JSC10 & 0.58 & & & \\
\hline RL_JSC11 & 0.85 & & & \\
\hline Knowledge Integration Capability (KIC) & 0.95 & 0.88 & 0.84 & 0.57 \\
\hline RL_KIC12 & 0.66 & & & \\
\hline RL_KIC13 & 0.79 & & & \\
\hline RL_KIC14 & 0.77 & & & \\
\hline RL_KIC15 & 0.62 & & & \\
\hline RL_KIC16 & 0.81 & & & \\
\hline RL KIC17 & 0.83 & & & \\
\hline
\end{tabular}


Table 2. Measurement model: discriminant validity

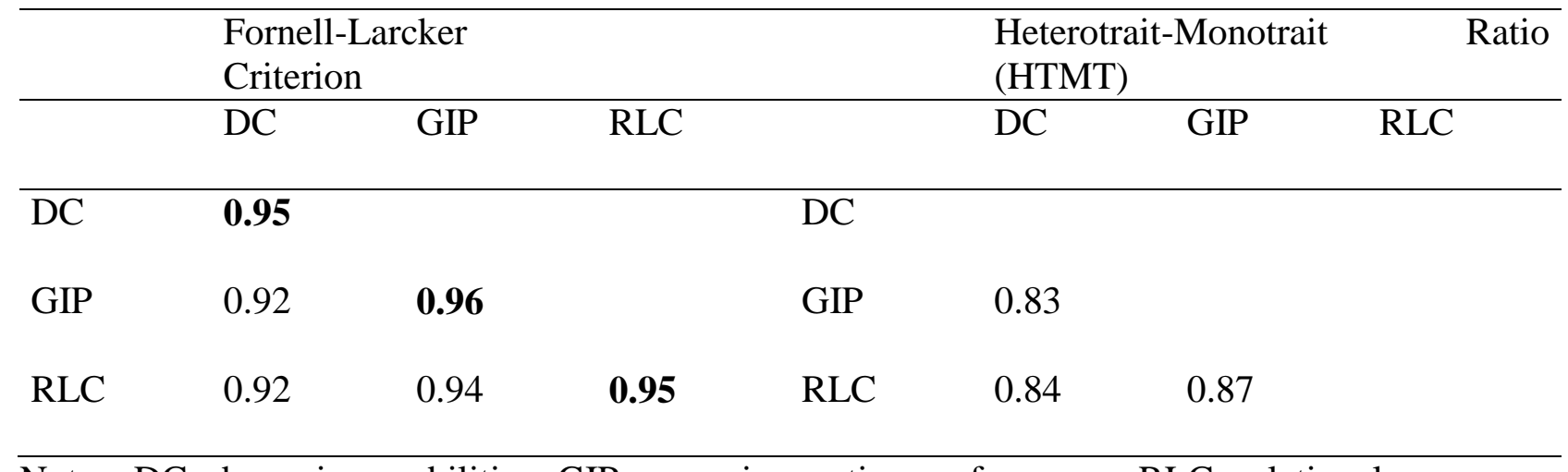

Notes: DC: dynamic capabilities; GIP: green innovation performance; RLC: relational learning capabilities. Fornell-Larcker Criterion: Diagonal elements (Bold) are the square root of the variance shared between the constructs and their measures (AVE). Off-diagonal elements are the correlations among constructs. For discriminant validity, diagonal elements should be larger than off-diagonal elements.

\subsection{Structural model results}

The study assesses the structural model on the basis of the algebraic sign, magnitude, and significance of the structural path coefficients. The $\mathrm{R}^{2}$ values assess predictive significance. Table 3 shows the explained variance $\left(\mathrm{R}^{2}\right)$ in the endogenous variables and the path coefficients for the two models under study (model 1 with direct relationship and model 2 with indirect or mediating effect). Following Hair et al.'s (2011) operation, this study uses a resampling bootstrapping (5000 resamples) to generate the standard errors and t-values (t-statistics). These results allow to check the significance statistics of the hypothetical relationships.

The three direct effects in Figure $1 \mathrm{~b}$ (model 2) are significant. Model 1 (Figure 1a) describes a positive direct effect of DC on GIP $(c=0.93$; $t$-value $=75.06)$. However, in the presence of RLC as a mediator variable (H4), the direct DC-GIP relationship diminishes. Thus, model 2 (Figure $1 \mathrm{~b}$ ) shows how the direct relationship between DC 
and GIP, although significant, is lower than the relationship in model 1 ( $\mathrm{c}=0.397$; $\mathrm{t}-$ value $=4.428)$. These results support the mediation hypothesis.

Figure 1. Structural model

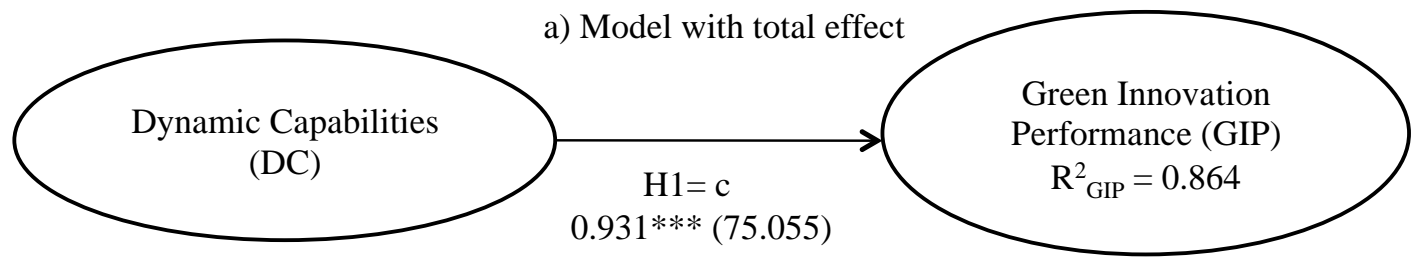

b) Model with an indirect effect

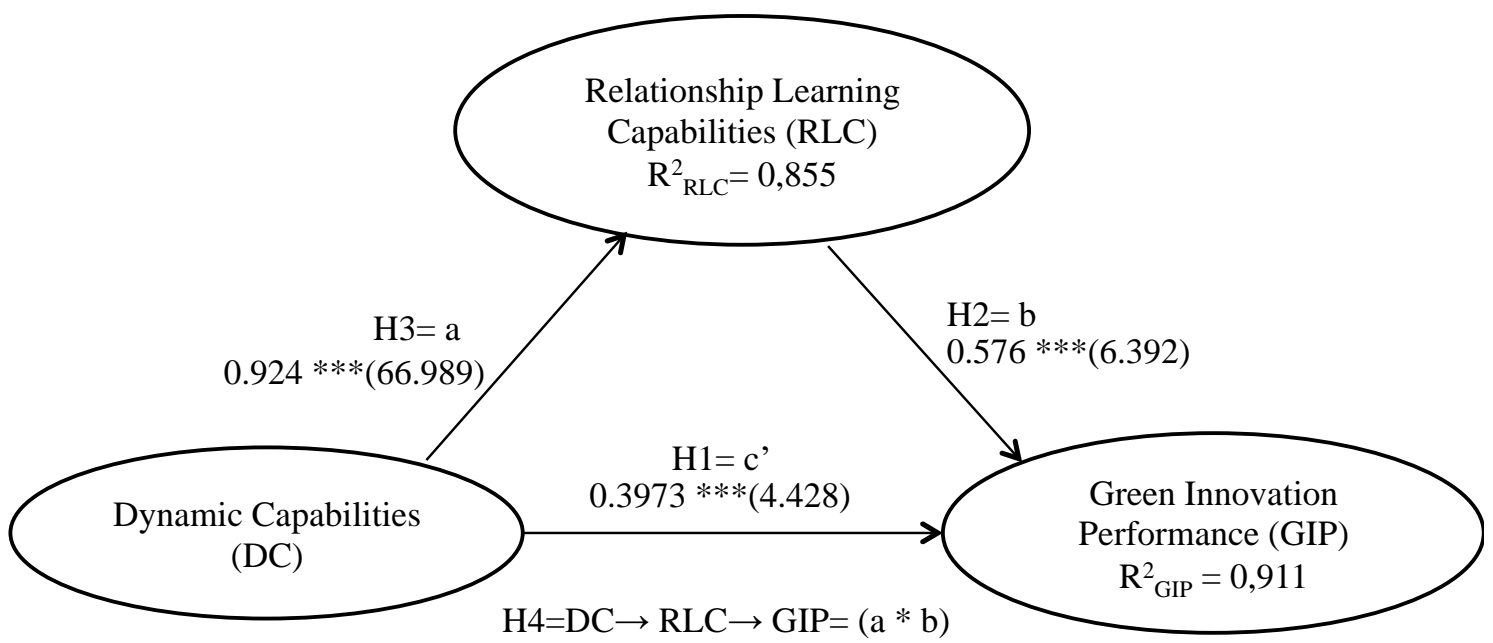

Table 3 shows that the indirect effect of DC on GIP via RLC is consistently positive and increases with increasing levels of RLC. Bootstrap confidence interval to the $95 \%$ for the indirect effect is always greater than zero (Baron \& Kenny, 1986). Therefore, RLC mediates the relationship between DC and GIP. Following Williams and MacKinnon's (2008) proposals, the study uses the bootstrapping technique to test the mediation effect. Chin (2010) suggests using the specific model in question including both direct and indirect paths, performing N-bootstrap resampling, and finally multiplying the direct paths that make up the indirect path under evaluation. This study's 5000 resamples also generate 95\% confidence intervals (percentile) for the mediators (Table 3) (Picón et al., 2014). 
Table 3. Structural model results

\section{Model 1}

$$
\begin{aligned}
\mathrm{R}_{\text {GIP }}^{2}=0.864 & \mathrm{R}_{\mathrm{GIP}}^{2}=0.91 \\
\mathrm{R}_{\mathrm{RLC}}^{2} & =0.85
\end{aligned}
$$

\section{Percentile}

Relationships Path coefficient Support Path coefficient Bootstrap 95\% CI Support

\begin{tabular}{lllllll}
\hline H1: DC $\rightarrow$ GIP & $0.93 * * *(75.05)$ & Yes & $0.39 * * *(4.42)$ & 0.20 & 0.57 & Yes \\
H2: RLC $\rightarrow$ GIP & & $0.92 * * *(66.98)$ & 0.89 & 0.94 & Yes \\
H3: DC $\rightarrow$ RLC & & $0.57 * * *(6.39)$ & 0.40 & 0.76 & Yes
\end{tabular}

Notes: DC: Dynamic capabilities; GIP: Green innovation performance; RLC: Relationship learning capabilities.

$\mathrm{t}$ values in parentheses: $\mathrm{t}(0.05,4999)=1.645 ; \mathrm{t}(0.01,4999)=2.327 ; \mathrm{t}(0.001,4999)=$ 3.092.

$* \mathrm{p}<0.05 . * * \mathrm{p}<0.01 . * * * \mathrm{p}<0.001$.

\section{Conclusions}

Several studies argue the existence of a direct link between firms' capabilities and financial performance (Karna et al., 2015; Teece, 2007; Zahra et al., 2006). However, no studies focus on the influence of the internal capabilities on other outcome' measures such as GIP. In comparison to conventional innovation and new product development, the study of green innovation is relatively new in the academe field even though scholars' interest on green innovation has grown in recent years (e.g., Chung \& Tsai, 2007; Pujari et al., 2003; Rehfeld et al., 2007). Building on previous literature, this study develops a research model that links DC, RLC, and GIP with the purpose of 
clarifying the existing relationships between DC and GIP and assessing whether new ordinary capabilities (RLC) mediate this link. This study is in line with other works that focus on the outcomes of firm' capabilities, contributing to the debate of fostering green and competitive firms (e.g., Chen \& Chang, 2013; Chen et al. 2006; Lefebvre et al. 2003; Shrivastava 1995).

The results suggest that both the direct effect and indirect effect of DC and RLC on GIP are positive and significant. Furthermore, the structural model supports that DC influence GIP by reconfiguring RLC, thus supporting the indirect effect of DC-GIP and the important mediator role of RLC.

This article makes three contributions to the literature. First, by making an explicit distinction between DC and a new OC (RLC), the study clarifies the nature of green innovation. Second, the study tests the effect of DC and RLC through a survey research with a sample of 112 firms on the GIP; a new measure of performance in the literature on this topic. Third, the mediation model provides practical steps for managers with an interest in dynamic and relationship learning capabilities supporting green innovation.

The study has some limitations. First, this study provides only a photo of continuing processes. Consequently, this study does not investigate the intricacies of the processes and capabilities over time. Future research should incorporate a longitudinal study that takes measures at different points in time and proves the relations established in the theoretical model. Second, although the study defines the constructs as rigorously as possible, these definitions come from appropriate literature in which specialists validate them, and thus are only proxies for underlying immeasurable latent phenomena. For successive research, the use of supplementary items may aid to apprehend the fruitfulness of the constructs addressed in this investigation. Third, the model in this study does not capture possible moderating effects of environmental turbulence. 
Companies competing in the same industry face similar input and output market as well as technological conditions, thus defining the task environment in which firms operate. Previous research shows that the influence of cognitive issues on individual, group, and organizational performance can change considerably depending on environmental conditions. Additionally, other factors or variables absent in this study may affect the constructs discussed herein.

\section{References}

Ambrosini, V., \& Bowman, C. (2009). What are dynamic capabilities and are they a useful construct in strategic management? International Journal of Management Reviews, 11(1), 29-49.

Aragón-Correa, J. A. (1998). Strategic proactivity and firm approach to the natural environment. Academy of Management Journal, 41, 556-567.

Baron, R. M., \& Kenny, D. A. (1986). The moderator-mediator variable distinction in social psychological research: Conceptual, strategic, and statistical considerations. Journal of Personality and Social Psychology, 51(6), 11-73.

Barroso, C., Cepeda, G., \& Roldán, J. L., (2010). Applying maximum likelihood and PLS on different sample sizes: studies on SERVQUAL model and employee behaviour model. In Esposito Vinzi, V., Chin, W.W., Henseler, J., et al. (Eds.), Handbook of Partial Least Squares: Concepts, Methods and Applications. Springer-Verlag, Berlin, 427-447.

Bossink, B. A. G. (2002). The development of co-innovation strategies: Stages and interaction patterns in interfirm innovation. $R \& D$ Management, 32(4), 311-320.

Carmines, E. G., \& Zeller, R. A. (1979). Reliability and validity assessment (Vol. 17). Sage Publications. 
Cepeda, G., Vera, D. (2007). Dynamic capabilities and operational capabilities: A knowledge management perspective. Journal of Business Research, 60(5), 426437.

Chen, Y. S., Lai, S. B., \& Wen, C. T. (2006). The influence of green innovation performance on corporate advantage in Taiwan. Journal of Business Ethics, 67(4), 331-339.

Chen, Y. S. (2008). The driver of green innovation and green image - green core competence. Journal of Business Ethics, 8(3), 531-543.

Chen, Y. S., \& Chang, C. H. (2013). The determinants of green product development performance: Green dynamic capabilities, green transformational leadership, and green creativity. Journal of Business Ethics, 116(1), 107-119.

Chesbrough, H. (2003). Open innovation: The new imperative for creating and profiting from technology. Cambridge, MA: Harvard Business School Publishing.

Cheung, M.-S., Myers, M. B., \& Mentzer, J. T. (2011). The value of relational learning in global buyer-supplier exchanges: A dyadic perspective and test of the piesharing premise. Strategic Management Journal, 32, 1061-1082.

Chin, W. W. (2010). How to write up and report PLS analyses. In V. Esposito Vinzi, W.W. Chin, J. Henseler, \& H. Wang (Eds.) Handbook of Partial Least Squares Concepts, Methods and Applications, Springer, Dordrecht, 645-689.

Chin, W. W., \& Gopal, A. (1995). Adoption intention in GSS: Relative importance of beliefs. ACM SigMIS Database, 26(2-3), 42-64.

Chung, Y., \& Tsai, C. (2007). The effect of green design activities on new product strategies and performance: An empirical study among high-tech companies. International Journal of Management, 24(2), 276-288. 
Doz, Y. L., Olk, P. M., \& Smith Ring, P. (2000). Formation processes of R\&D consortia; which path to take: Where does it lead? Strategic Management Journal, 21(3), 239-266.

Fornell, C., \& Larcker, D. F. (1981). Evaluating structural equation models with unobservable variables and measurement error. Journal of Marketing Research, 18(1), 39-50.

Hair, J. F., Hultt, G. T. M., Ringle, C., \& Sarstedt, M. (2014). A primer on Partial Least Squares Structural Equation Modeling (PLS-SEM). Los Angeles: SAGE Publications, Inc.

Hair, J. F., Ringle, C. M., \& Sarstedt, M. (2011). PLS-SEM: Indeed a silver bullet. Journal of Marketing theory and Practice, 19(2), 139-152.

Helfat, C., \& Peteraf, M. (2003). The dynamic resource-based view: Capability lifecycles. Strategic Management Journal, 24(10), 997-1010.

Helfat, C., Finkelstein, S., Mitchell, W., Peteraf, M., Singh, H., Teece, D., \& Winter, S. G. (2007). Dynamic Capabilities: Understanding Strategic Change in Organizations. Malden, MA: Wiley-Blackwell.

Henseler, J., Ringle, C. M., \& Sarstedt, M. (2015). A new criterion for assessing discriminant validity in variance-based structural equation modeling. Journal of the Academy of Marketing Science, 43(1), 115-135.

Karna, A., Richter, A., \& Riesenkampff, E. (2015). Revisiting the role of the environment in the capabilities-financial performance relationship: A metaanalysis. Strategic Management Journal, Published online EarlyView in Wiley Online Library (wileyonlinelibrary.com) DOI: 10.1002/smj.2379 
Laforet, S. (2009). Effects of size, market and strategic orientation on innovation in non-high-tech manufacturing SMEs. European Journal of Marketing, 43(1-2), $188-212$.

Lefebvre, É., Lefebvre, L. A., \& Talbot, S. (2003). Determinants and impacts of environmental performance in SMEs. R\&D Management, 33(3), 263-283.

Makadok, R. (2001). Toward a synthesis of the resource-based and dynamic capability views of rent creation. Strategic Management Journal, 22(5), 487-505.

Ngai, E. W. T., Jin, C., \& Liang, T. (2008). A qualitative study of inter-organizational Knowledge management in complex products and Systems development. $R \& D$ Management, 38(4), 421-440.

Nunnally, J. C., \& Bernstein, I. H. (1994). The assessment of reliability. Psychometric Theory, 3, 248-292.

Pavlou, P. A., \& El Sawy, O. A. (2011). Understanding the elusive black box of dynamic capabilities. Decision Sciences, 42(1), 239-273.

Pérez-Valls, M., Céspedes-Lorente, J., \& Moreno-García, J. (2015). Green Practices and Organizational Design as Sources of Strategic Flexibility and Performance. Business Strategy and the Environment. Published online EarlyView in Wiley Online Library (wileyonlinelibrary.com) DOI: 10.1002/bse.1881.

Petruzzelli, A. M., Dangelico, R. M., Rotolo, D., \& Albino, V. (2011). Organizational factors and technological features in the development of green innovations: Evidence from patent analysis, Innovation: Management. Policy \& Practice, 13(3), 291-310.

Picón, A., Castro, I., \& Roldán, J. L. (2014). The relationship between satisfaction and loyalty: A mediator analysis. Journal of Business Research, 67(5), 746-751. 
Porter, M., \& Reinhardt, F. L. (2007). A strategic approach to climate. Harvard Business Review, 85(10), 22-26.

Powell, W. (1998). Learning from Collaboration: Knowledge and Networks in the Biotechnology and Pharmaceutical Industries. California Management Review, 40, 228-240.

Prahalad, C. K., \& Ramaswamy, V. (2004). The future of competition. Cambridge, MA: Harvard Business School Press.

Pujari, D., Wright, G., \& Peattie, K. (2003). Green and competitive - Influences on environmental wew product development performance. Journal of Business Research, 56(8), 657-671.

Rehfeld, K-M., Rennings, K., \& Ziegler, A. (2007). Integrated product policy and environmental product innovations: An empirical analysis. Ecological Economics, 61(1), 91-100.

Reinartz, W., Haenlein, M., \& Henseler, J. (2009). An empirical comparison of the efficacy of covariance-based and variance-based SEM. International Journal of Research in Marketing, 26(4), 332-344.

Ringle, C. M., Wende, S., \& Will, A. (2005). SmartPLS 2.0 (M3) beta. Retrieved from: http:// www.smartpls.de (at Hamburg).

Roldán, J. L., \& Sánchez-Franco, M. J. (2012). Variance-based structural equation modeling: Guidelines for using partial least squares in information systems research. In Mora, M. (Ed.) Research methodologies, innovations and philosophies in software systems engineering and information systems (pp. 193221). Hershey, PA: IGI Global.

Shrivastava, P. (1995). Environmental technologies and competitive advantage, Strategic Management Journal, 16(S1), 183-200. 
Selnes, F., \& Sallis, J. (2003). Promoting relationship learning. Journal of Marketing, 67(1), 80-95.

Teece, D. J. (2007). Explicating dynamic capabilities: The nature and microfoundations of (sustainable) enterprise performance. Strategic Management Journal, 28(8), $1319-1350$.

Teece, D. J., Pisano, G., \& Shuen, A. (1997). Dynamic capabilities and strategic management. Strategic Management Journal, 18(7), 509-533.

Williams, J., \& MacKinnon, D. P. (2008). Resampling and distribution of the product methods for testing indirect effects in complex models. Structural Equation Modeling, 15(1), 23-51.

Winter, S. (2003). Understanding dynamic capabilities. Strategic Management Journal, 24(10), 991-995.

Zahra, S. A., Sapienza, H. J., \& Davidsson, P. (2006). Entrepreneurship and dynamic capabilities: A review, model and research agenda. Journal of Management Studies, 43(4), 917-955.

Zollo, M., \& Winter, S. (2002). Deliberate learning and the evolution of dynamic capabilities. Organizational Science, 13(2), 339-351. 